Eylem Demircioglu ${ }^{1}$

Aysun Sofuoglu ${ }^{2}$

Mustafa Odabasi ${ }^{1}$

${ }^{1}$ Faculty of Engineering, Department of Environmental Engineering, Dokuz Eylul University, Izmir, Turkey

${ }^{2}$ Faculty of Engineering, Department of Chemical Engineering, Izmir Institute of Technology, Gulbahce-Urla, Turkey
Research Article

\section{Atmospheric Concentrations and Phase Partitioning of Polycyclic Aromatic Hydrocarbons in Izmir, Turkey}

Ambient air polycyclic aromatic hydrocarbon (PAH) samples were collected at a suburban $(n=63)$ and at an urban site $(n=14)$ in Izmir, Turkey. Average gas-phase total PAH ( $\sum_{14} \mathrm{PAH}$ ) concentrations were $23.5 \mathrm{ng} \mathrm{m}^{-3}$ for suburban and $109.7 \mathrm{ng} \mathrm{m}^{-3}$ for urban sites while average particle-phase total PAH concentrations were 12.3 and $34.5 \mathrm{ng} \mathrm{m}^{-3}$ for suburban and urban sites, respectively. Higher ambient PAH concentrations were measured in the gas-phase and $\sum_{14} \mathrm{PAH}$ concentrations were dominated by lower molecular weight PAHs. Multiple linear regression analysis indicated that the meteorological parameters were effective on ambient PAH concentrations. Emission sources of particle-phase PAHs were investigated using a diagnostic plot of fluorene (FLN)/ (fluorine + pyrene; PY) versus indeno[1,2,3-cd] PY/(indeno[1,2,3-cd $] \mathrm{PY}+$ benzo[g,h,i]perylene) and several diagnostic ratios. These approaches have indicated that traffic emissions (petroleum combustion) were the dominant PAH sources at both sites for summer and winter seasons. Experimental gas-particle partition coefficients $\left(K_{\mathrm{P}}\right)$ were compared to the predictions of octanol-air $\left(K_{\mathrm{OA}}\right)$ and soot-air $\left(K_{\mathrm{SA}}\right)$ partition coefficient models. The correlations between experimental and modeled $K_{\mathrm{P}}$ values were significant $\left(r^{2}=0.79\right.$ and 0.94 for suburban and urban sites, respectively, $p<0.01$ ). Octanol-based absorptive partitioning model predicted lower partition coefficients especially for relatively volatile PAHs. However, overall there was a relatively good agreement between the measured $K_{\mathrm{P}}$ and soot-based model predictions.

\footnotetext{
Keywords: Gas/particle partitioning; Octanol-air-based absorption model; Polycyclic aromatic hydrocarbon; Soot-air-based model
}

Received: July 5, 2010; revised: November 23, 2010; accepted: November 24, 2010

DOI: $10.1002 /$ clen.201000221

\section{Introduction}

Polycyclic aromatic hydrocarbons (PAHs) are a complex class of organic compounds containing two or more fused aromatic rings, and only carbon and hydrogen. PAHs are formed as a result of incomplete combustion and released into the environment through natural and anthropogenic sources. There are hundreds of individual PAHs in the environment, however, only 16 PAH compounds have been classified by the U.S. Environmental Protection Agency (USEPA) as priority pollutants [1]. At ambient temperatures, PAHs are solids. The general characteristics common to the class are high melting- and boiling-points, low vapor pressure, and very low water solubility [2].

Correspondence: Dr. A. Sofuoglu, Faculty of Engineering, Department of Chemical Engineering, Izmir Institute of Technology, 35430 GulbahceUrla, Turkey

E-mail: aysunsofuoglu@iyte.edu.tr

Abbreviations: ANT, anthracene; BaA, benz $[a]$ anthracene; BaP, benzo[a]pyrene; BbF, benzo[b]fluoranthene; BghiP, benzo[g,h,i]perylene; BkF, benzo[k]fluoranthene; CHR, chrysene; CRB, carbazole; DahA, dibenzo[a,h]anthracene; FL, fluoranthene; FLN, fluorene; IcdP, indeno[1,2,3-cd]pyrene; MLR, multiple linear regression; OM, organic matter; PAH, polycyclic aromatic hydrocarbon; PHE, phenanthrene; PUF, polyurethane foam; PY, pyrene; TSP, total suspended particles.
Atmospheric PAHs are distributed between gas and particlephases. The partitioning of PAHs between the gas and particle-phases is an important factor affecting their removal processes [2, 3]. PAHs are removed from the atmosphere by transformation, wet and dry deposition, air-water exchange, and air-soil exchange.

Atmospheric levels of PAHs have been widely measured around the world [4-15]. Despite their environmental relevance, only a few studies have been conducted in Turkey on the atmospheric PAH levels [14-19]. The objectives of this study were to investigate (1) the ambient air concentrations of 14 PAHs and their temporal variations in Izmir, Turkey, (2) the effect of meteorological parameters on ambient concentrations, (3) the possible sources of PAHs in the study area, and (4) their gas/particle partitioning.

\section{Materials and methods}

\subsection{Sampling program and collection}

Ambient air samples were collected at two sampling sites (suburban and urban) in Izmir (Fig. 1). The suburban samples were collected on a 4-m high platform located on the Kaynaklar Campus of the Dokuz Eylul University, $\sim 10 \mathrm{~km}$ southeast of Izmir's center. This site is relatively far from any settlement zones or industrial facilities. 


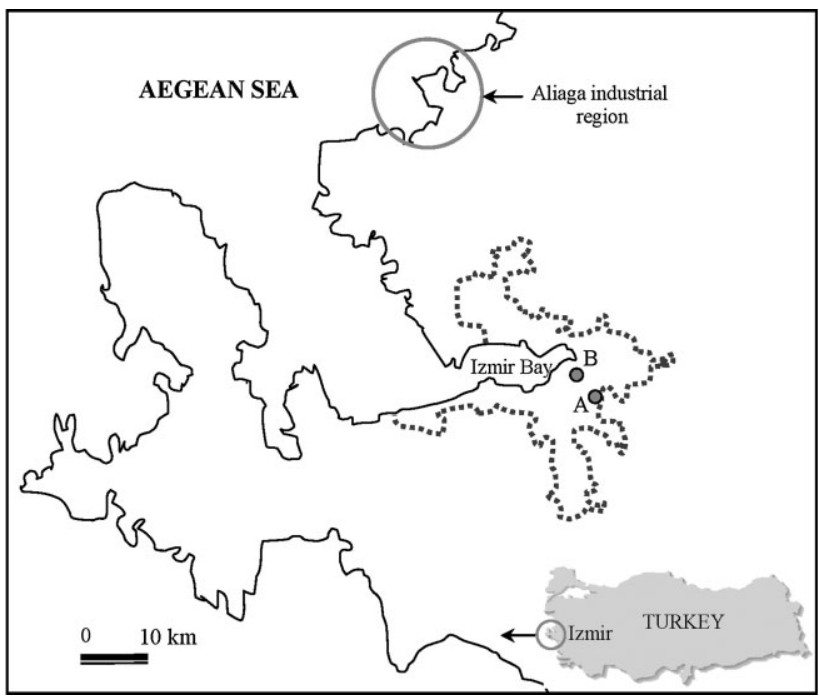

Figure 1. Map of the Izmir showing the sampling sites. (A) Suburban sampling site, (B) Urban sampling site. Dashed line is border of densely populated areas.

There are residential areas located approximately $2 \mathrm{~km}$ southwest and a highway located $0.5 \mathrm{~km}$ south of the sampling site. Land cover in the immediate area is a young coniferous forest. There are steel plants, a petroleum refinery, and petrochemical industry located $45 \mathrm{~km}$ to the northwest. The nearest industrial facility is a cement work about $10 \mathrm{~km}$ at north and an open road gravel storage site nearly $3 \mathrm{~km}$ at the east. Urban samples were collected from Yesildere site located near a main street with heavy traffic and residential areas.

Sixty-three ambient air samples were collected between May 2003 and May 2004 at the suburban site. Another two additional sampling campaigns were conducted between March 17-24, 2004 (winter) and July 15-22, 2004 (summer) at the urban site. Successive seven ambient air samples were collected for each sampling period. All samples were collected when there was no rain. Samples were also collected to determine the total suspended particles (TSP) and their organic matter $(\mathrm{OM})$ content. Meteorological data were obtained from a 10-m high tower located at the suburban sampling site.

Air samples were collected using a modified high-volume sampler model GPS-11 (Thermo-Andersen Inc.). Particles were collected on 10.5-cm diameter quartz filters and the gas-phase compounds were collected in a modified cartridge containing XAD-2 resin placed between layers of polyurethane foam (PUF). Concurrently, particle samples were collected on 11-cm diameter glass fiber filters using another high-volume sampler to determine TSP and its OM content. The average sampling volumes for $\mathrm{PAHs}$ were $173 \pm 44$ and $277 \pm 62 \mathrm{~m}^{3}$ and the average sampling volume for TSP were $40.5 \pm 8.5$ and $93.9 \pm 13.0 \mathrm{~m}^{3}$ at suburban and urban sites, respectively. Sampling time ranged between $11 \mathrm{~h}$ (suburban) and $22 \mathrm{~h}$ (urban).

Prior to sampling, quartz filters were baked at $450^{\circ} \mathrm{C}$ overnight. Then, they were allowed to cool to room temperature in a desiccator. PUF cartridges (two PUF plugs + XAD-2 resin layer) were cleaned by Soxhlet extraction using an acetone/hexane mixture (1:1) for $12 \mathrm{~h}$, dried in an oven at $70^{\circ} \mathrm{C}$, and stored in glass jars capped with Teflonlined lids. After sampling, PS-1 filters and PUF cartridges were stored at $-20^{\circ} \mathrm{C}$ in their containers.

\subsection{Sample preparation and analysis}

Ambient air samples (filters and PUF cartridges) were separately Soxhlet extracted for $12 \mathrm{~h}$ with a mixture of 20:80 dichloromethane (DCM):petroleum ether (PE). Prior to extraction, all samples were spiked with PAH surrogate standards (naphthalene-d8, acenaphthene-d10, phenanthrene (PHE)-d10, chrysene-d12, and perylened12) to monitor the analytical recovery efficiencies. The extract volumes were reduced and the solvent was exchanged into hexane using a rotary evaporator and a high-purity $\mathrm{N}_{2}$ stream. After concentrating to $2 \mathrm{~mL}$, samples were cleaned up and fractionated on an alumina-silicic acid column containing $3 \mathrm{~g}$ of silicic acid (deactivated with $3 \%$ deionized water) and $2 \mathrm{~g}$ of alumina (deactivated with $6 \%$ deionized water). The column was pre-washed with $20 \mathrm{~mL}$ of DCM followed by $20 \mathrm{~mL}$ of PE. Then, the sample in $2 \mathrm{~mL}$ hexane was added to the column and PAHs were eluted with $20 \mathrm{~mL}$ DCM. The final extracts were solvent exchanged into hexane and concentrated to $1 \mathrm{~mL}$ under a stream of $\mathrm{N}_{2}$

Prior to sampling for TSP, baked and cooled glass fiber filters were weighed using a microbalance capable of weighing $0.1 \mathrm{mg}$. After collection of sample, they were kept in a desiccator overnight and reweighed. TSP was obtained by subtracting the initial weight from the final weight. OM contents of the particles were determined by subtracting the filters baked in a furnace for $1 \mathrm{~h}$ at $450^{\circ} \mathrm{C}$ from the initial weight before baking.

All samples were analyzed for $14 \mathrm{PAHs}$ including fluorene (FLN), PHE, anthracene (ANT), carbazole (CRB), fluoranthene (FL), pyrene (PY), benz $[a]$ anthracene $(\mathrm{BaA})$, chrysene (CHR), benzo[b]fluoranthene $(\mathrm{BbF})$, benzo[k]fluoranthene $(\mathrm{BkF})$, benzo[a]pyrene $(\mathrm{BaP})$, indeno[1,2,3$c d]$ pyrene (IcdP), dibenzo[a, $h]$ anthracene (DahA), and benzo[g, $h, i]$ perylene (BghiP) with an Agilent 6890N GC equipped with a mass selective detector (Agilent 5973 inert MSD). A capillary column (HP5-ms, $30 \mathrm{~m}, 0.25 \mathrm{~mm}, 0.25 \mu \mathrm{m}$ ) was used. The initial oven temperature was held at $50^{\circ} \mathrm{C}$ for $1 \mathrm{~min}$ and raised to $200^{\circ} \mathrm{C}$ at $25^{\circ} \mathrm{C} \mathrm{min}{ }^{-1}$, $200-300^{\circ} \mathrm{C}$ at $8^{\circ} \mathrm{C} \mathrm{min}^{-1}$, and was held for $5.5 \mathrm{~min}$. The injector, ion source, and quadrupole temperatures were 295,300 , and $180^{\circ} \mathrm{C}$, respectively. High-purity helium was used as the carrier gas at constant flow mode $\left(1.5 \mathrm{~mL} \mathrm{~min}^{-1}\right)$. The MSD was run in selected ionmonitoring mode. All compounds were identified based on their retention times, target, and qualifiers ions. The quantification was based on internal standard calibration procedure.

\subsection{Quality control}

Average recoveries of PAH surrogate standards were $68 \pm 14 \%$ for PHE-d10 $(n=147), 82 \pm 14 \%$ for CHR-d $12(n=154)$, and $77 \pm 19 \%$ for perylene-d12 $(n=152)$ for all ambient air samples. The recoveries of target compounds were also tested by matrix spiking experiments and average recovery efficiencies were between $88 \pm 22 \%$ (DahA) and $121 \pm 6 \%$ (IcdP) (overall average \pm SD, $107 \pm 16 \%$ ).

Blank PUF cartridges and air filters were routinely placed in the field to determine if there was any contamination during sampling, sample handling, and preparation. PHE had the highest amount in blanks with an average of $123 \pm 43 \mathrm{ng}$ for PUFs and $79 \pm 21 \mathrm{ng}$ for air filters. Average blank amounts for PUFs and air filters were $11 \pm 10$ and $8 \pm 13 \%$ of the sample amounts for all analyzed PAHs, respectively. Instrumental detection limits (IDL) were determined from linear extrapolation from the lowest standard in calibration curve using the area of a peak having a signal/noise ratio of 3 . The quantifiable PAH amount was approximately $0.15 \mathrm{pg}$ for $1 \mu \mathrm{L}$ injection. IDL 
was used for the compounds that were not detected in blanks. The limit of detection of the method (LOD) was defined as the mean blank mass plus three standard deviations. LODs for $14 \mathrm{PAH}$ compounds ranged from $2 \mathrm{ng}(\mathrm{BaP})$ to $253 \mathrm{ng}$ (PHE) for PUFs and $2 \mathrm{ng}(\mathrm{BaA})$ to $143 \mathrm{ng}$ (PHE) for PS-1 filters. These values correspond to air concentrations of $0.01 \mathrm{ng} \mathrm{m}^{-3}$ (BaP) to $0.9 \mathrm{ng} \mathrm{m}^{-3}$ (PHE) for PUFs, and $0.01 \mathrm{ng} \mathrm{m}^{-3}$ (BaA) to $0.5 \mathrm{ng} \mathrm{m}^{-3}$ (PHE) for PS-1 filters. Sample quantities exceeding the LOD were quantified and blank-corrected by subtracting the mean blank amount from the sample amount for all samples.

Six levels of calibration standards $(0.04,0.4,1.0,4.0,6.0$, and $10.0 \mu \mathrm{g} \mathrm{mL}^{-1}$ ) were used to calibrate the GC/MS system. In all cases, the $r^{2}$ of the calibration curve was $\geq 0.999$. System performance was verified by the analysis of the mid-point calibration standard for every $24 \mathrm{~h}$ during the analysis period.

Concurrent blank filters were run for each TSP and OM sample to determine if there was any contamination during sample handling and preparation, and to account for probable interferences (i.e., weight loss of filters at high temperatures) in OM determination. The average weight loss of blank filters $(0.38 \mathrm{mg})$ was significantly lower than the average weight loss of the samples $(2.5 \mathrm{mg})$ indicating that the interference was not significant in OM determination.

\section{Results and discussion}

\subsection{Ambient PAH concentrations}

Gas and particle-phase concentrations of individual PAHs at all sites are presented in Tab. 1. Average gas-phase total PAH $\left(\sum_{14} \mathrm{PAH}\right)$ concentrations were $23.5 \mathrm{ng} \mathrm{m}^{-3}$ for suburban and $109.7 \mathrm{ng} \mathrm{m}^{-3}$ for urban sites while average particle-phase total PAH concentrations were 12.3 and $34.5 \mathrm{ng} \mathrm{m}^{-3}$ for suburban and urban sites, respectively. Measured average total (gas + particle) PAH concentrations were $36 \pm 39$ and $144 \pm 163 \mathrm{ng} \mathrm{m}^{-3}$ for suburban and urban sites in this study. The concentrations of PAHs may have a diurnal variation. This may be a confounding factor for the comparison of
Table 1. Ambient air concentrations $\left(\mathrm{ng} \mathrm{m}^{-3}\right)$ of individual PAHs for suburban and urban sites (average \pm SD)

\begin{tabular}{lccccc}
\hline \multirow{2}{*}{ PAHs } & \multicolumn{2}{c}{ Suburban } & & \multicolumn{2}{c}{ Urban } \\
\cline { 2 - 3 } \cline { 5 - 6 } & Gas & Particle & Gas & Particle \\
\hline FLN & $4.1 \pm 4.5$ & $0.6 \pm 1.0$ & & $12.5 \pm 10.3$ & $0.1 \pm 0.1$ \\
PHE & $11.7 \pm 12.1$ & $1.9 \pm 2.6$ & & $40.8 \pm 36.2$ & $1.0 \pm 0.8$ \\
ANT & $0.5 \pm 0.7$ & $0.1 \pm 0.1$ & & $5.6 \pm 6.2$ & $0.1 \pm 0.1$ \\
CRB & $0.4 \pm 0.8$ & $0.2 \pm 0.3$ & & $1.0 \pm 2.0$ & $0.1 \pm 0.1$ \\
FL & $3.7 \pm 4.1$ & $1.5 \pm 2.5$ & & $27.3 \pm 43.5$ & $2.8 \pm 3.7$ \\
PY & $2.4 \pm 2.4$ & $1.4 \pm 2.2$ & & $20.2 \pm 27.0$ & $3.1 \pm 4.2$ \\
BaA & $0.1 \pm 0.1$ & $0.5 \pm 1.0$ & & $0.6 \pm 0.5$ & $3.0 \pm 4.8$ \\
CHR & $0.4 \pm 0.3$ & $1.5 \pm 2.5$ & & $1.6 \pm 1.0$ & $6.2 \pm 8.6$ \\
BbF & $0.05 \pm 0.04$ & $0.9 \pm 1.3$ & & $0.03 \pm 0.02$ & $3.4 \pm 4.1$ \\
BkF & $0.02 \pm 0.01$ & $0.8 \pm 1.2$ & & $0.02 \pm 0.01$ & $3.6 \pm 4.6$ \\
BaP & $0.02 \pm 0.02$ & $0.7 \pm 1.0$ & & $0.008 \pm 0.006$ & $3.1 \pm 4.7$ \\
IcdP & $0.01 \pm 0.01$ & $0.9 \pm 1.4$ & & $0.006 \pm 0.004$ & $3.4 \pm 4.5$ \\
DahA & $0.02 \pm 0.03$ & $0.4 \pm 0.7$ & & $0.003 \pm 0.001$ & $1.3 \pm 1.9$ \\
BghiP & $0.03 \pm 0.04$ & $0.9 \pm 1.1$ & & $0.008 \pm 0.005$ & $3.4 \pm 3.8$ \\
$\sum_{14}$ PAH & $23.5 \pm 23.8$ & $12.3 \pm 16.2$ & & $109.7 \pm 111.7$ & $34.5 \pm 45.7$ \\
\hline
\end{tabular}

the measurement results from the urban site (for $22 \mathrm{~h}$ ) and suburban site (for $11 \mathrm{~h}$ ). The values measured in the present study were within the range of previously reported values in other urban and industrial sites around the world (Tab. 2). Total $\sum_{14} \mathrm{PAH}$ concentrations measured at the suburban, and urban sites in the present study are considerably lower than those reported for urban sites in Bursa [14] and in Chicago [5] while they are significantly higher than those reported for urban Athens [8]. The PAH levels measured at the suburban site in this study are similar to those reported for an industrial site in Izmir, for urban Heraklion, for industrial sites in Fuji and Shimizu, and for urban/industrial Baltimore (Tab. 2).

The gas/particle phase distributions indicated that about 69 and $81 \%$ of $\sum{ }_{14} \mathrm{PAHs}$ were in the gas-phase for the suburban and urban sites, respectively. Because of their higher volatility, low to medium molecular weight PAHs (3-5 rings) were more abundant in the gasphase similar to the previous studies $[10,14,20,21]$.

Table 2. Total PAH concentrations $\left(\sum_{n} \mathrm{PAH}, \mathrm{ng} \mathrm{m}^{-3}\right)$ measured around the world

\begin{tabular}{|c|c|c|c|c|c|}
\hline Location & $\begin{array}{l}\text { Number of PAHs } \\
\text { included in } \sum \text { PAH }(n)\end{array}$ & Industrial & Urban & $\begin{array}{l}\text { Suburban/ } \\
\text { Rural }\end{array}$ & References \\
\hline Taichung, Taiwan & 13 & 678.7 & 476.7 & $319.4^{\mathrm{a})}$ & {$[21]$} \\
\hline Chicago, USA & 13 & & 351.8 & & {$[5]$} \\
\hline Bursa, Turkey & 13 & 224.6 & & & [14] \\
\hline Rome, Italy & 12 & & 162.4 & & [12] \\
\hline London, UK & 11 & & 160.6 & & [4] \\
\hline Stevenage, UK & 11 & 90.3 & & & [4] \\
\hline Seoul, Korea & 13 & & 67.3 & & [9] \\
\hline Heraklion, Greece & 12 & & 51.5 & & [13] \\
\hline Fuji, Japan & 13 & 46 & & & [10] \\
\hline Baltimore, USA & 13 & & 24 & & [6] \\
\hline Athens, Greece & 10 & 15.4 & & & [8] \\
\hline New Jersey, USA & 10 & & 27.5 & & [7] \\
\hline Izmir, Turkey & 14 & 43.5 & & & [15] \\
\hline Zonguldak, Turkey & 14 & & 298 & & [16] \\
\hline Konya, Turkey & 16 & & 206 & & {$[17]$} \\
\hline Bursa, Turkey & 15 & & 298 & & [18] \\
\hline Bursa, Turkey & 14 & & $152^{\mathrm{b})}-1249^{\mathrm{c})}$ & & [19] \\
\hline Izmir, Turkey & 14 & & 144 & 36 & \\
\hline
\end{tabular}

\footnotetext{
a) Rural area.

b) Non-heating season.

c) Heating season.
} 
Table 3. Summary of regression parameters for Eq. (1) for all sites and individual compounds

\begin{tabular}{|c|c|c|c|c|c|}
\hline & $m_{1}$ & $m_{2}$ & $m_{3}$ & $r^{2}$ & $n$ \\
\hline \multicolumn{6}{|c|}{ Suburban } \\
\hline FLN & $-0.28^{\mathrm{a})}$ & $-0.51^{\mathrm{a})}$ & 0.60 & 0.26 & 63 \\
\hline PHE & $-0.71^{\text {a) }}$ & $-1.53^{\mathrm{a})}$ & 2.39 & 0.24 & 63 \\
\hline ANT & $-0.05^{\mathrm{a})}$ & -0.04 & 0.06 & 0.31 & 63 \\
\hline CRB & 0.00 & 0.03 & 0.08 & 0.01 & 63 \\
\hline FL & $-0.39^{\text {a) }}$ & -0.42 & 0.67 & 0.25 & 63 \\
\hline PY & $-0.28^{\mathrm{a})}$ & -0.41 & 0.64 & 0.28 & 63 \\
\hline $\mathrm{BaA}$ & $-0.06^{\mathrm{a})}$ & -0.08 & 0.14 & 0.28 & 63 \\
\hline $\mathrm{CHR}$ & $-0.16^{\mathrm{a})}$ & $-0.26^{\mathrm{a})}$ & 0.40 & 0.26 & 63 \\
\hline $\mathrm{BbF}$ & $-0.07^{\mathrm{a})}$ & $-0.13^{\mathrm{a})}$ & 0.22 & 0.25 & 63 \\
\hline $\mathrm{BkF}$ & $-0.07^{\mathrm{a})}$ & $-0.12^{\mathrm{a})}$ & 0.20 & 0.27 & 63 \\
\hline $\mathrm{BaP}$ & $-0.05^{\mathrm{a})}$ & $-0.11^{\mathrm{a})}$ & 0.20 & 0.23 & 63 \\
\hline IcdP & $-0.06^{\mathrm{a})}$ & $-0.17^{\mathrm{a})}$ & 0.32 & 0.19 & 63 \\
\hline DahA & -0.02 & $-0.12^{\mathrm{a})}$ & $0.29^{\mathrm{a})}$ & 0.24 & 63 \\
\hline BghiP & $-0.05^{\mathrm{a})}$ & $-0.16^{\mathrm{a})}$ & 0.30 & 0.22 & 63 \\
\hline \multicolumn{6}{|l|}{ Urban } \\
\hline FLN & -0.27 & $-4.70^{\mathrm{a})}$ & 3.68 & 0.62 & 14 \\
\hline PHE & -0.14 & $-20.38^{\mathrm{a})}$ & 15.68 & 0.67 & 14 \\
\hline ANT & -0.41 & $-2.79^{\mathrm{a})}$ & $4.48^{\mathrm{a})}$ & 0.82 & 14 \\
\hline CRB & -0.05 & $-0.98^{\mathrm{a})}$ & 1.57 & 0.54 & 14 \\
\hline FL & -3.00 & -16.70 & $39.11^{\text {a) }}$ & 0.63 & 14 \\
\hline PY & -1.89 & $-12.03^{\text {a) }}$ & $26.03^{\mathrm{a})}$ & 0.67 & 14 \\
\hline $\mathrm{BaA}$ & -0.25 & $-2.49^{\mathrm{a})}$ & $4.34^{\mathrm{a})}$ & 0.76 & 14 \\
\hline CHR & -0.47 & $-4.45^{\mathrm{a})}$ & $7.08^{\mathrm{a})}$ & 0.78 & 14 \\
\hline $\mathrm{BbF}$ & -0.20 & $-1.91^{\mathrm{a})}$ & $2.70^{\mathrm{a})}$ & 0.74 & 14 \\
\hline $\mathrm{BkF}$ & -0.24 & $-2.08^{\mathrm{a})}$ & $3.27^{\mathrm{a})}$ & 0.74 & 14 \\
\hline $\mathrm{BaP}$ & -0.22 & $-2.21^{\mathrm{a})}$ & $3.91^{\text {a) }}$ & 0.75 & 14 \\
\hline IcdP & -0.17 & $-2.27^{\mathrm{a})}$ & $3.16^{\mathrm{a})}$ & 0.75 & 14 \\
\hline DahA & -0.06 & $-0.94^{\mathrm{a})}$ & $1.33^{\mathrm{a})}$ & 0.72 & 14 \\
\hline BghiP & -0.16 & $-1.80^{\mathrm{a})}$ & $2.44^{\mathrm{a})}$ & 0.73 & 14 \\
\hline
\end{tabular}

In the suburban site, PHE, FLN, FL, and PY accounted for 42, 14, 12, and $10 \%$ of $\Sigma_{14}$ PAHs in summer period while in urban site they were $41,12,14$, and $15 \%$ of $\Sigma_{14}$ PAHs. During winter, the contributions of PHE, FLN, FL, and PY in suburban and urban sites were $35,12,16$, and $11 \%, 26,8,22$, and $16 \%$ of $\Sigma_{14}$ PAHs, respectively. These percentages were similar to those reported previously $[5,15,20]$.

\subsection{Effect of meteorological parameters on gas- phase PAH concentrations}

The effect of wind speed and direction on atmospheric concentrations of individual PAHs was investigated using multiple linear regression (MLR) analysis [22]:

$C_{\mathrm{t}}=m_{1} T+m_{2} U+m_{3} \cos \mathrm{WD}+b$

where $C_{\mathrm{t}}$ is the total (gas + particle phase) PAH concentration $\left(\mathrm{ng} \mathrm{m}^{-3}\right), \mathrm{T}$ the average atmospheric temperature $\left({ }^{\circ} \mathrm{C}\right), \mathrm{U}$ the wind speed $\left(\mathrm{m} \mathrm{s}^{-1}\right)$, WD the predominant wind direction (radians) during the sampling period, and $m_{1}-m_{3}$, and $b$ are the regression parameters.

The results of MLR analysis are presented in Tab. 3. Temperature, wind speed, and wind direction together accounted for 1\% (CRB) to $31 \%$ (ANT), and $54 \%$ (CRB) to $82 \%$ (ANT) of the variability in the atmospheric PAH concentrations for suburban and urban sites, respectively. The $m_{1}$ values were insignificant for all PAHs for urban site. The $m_{1}$ values were statistically significant for all PAHs $(p<0.05)$ except CRB and DahA for suburban site. Generally negative $m_{1}$ values were obtained for PAHs indicated that their concentrations increased with decreasing temperature. This was probably due to increased PAH emissions from combustion sources like residential heating with decreased ambient temperature. For most of the compounds, $m_{2}$ had negative values and they were statistically significant for most of the compounds. This indicated that their concentrations decreased as the wind speed increased and advection was also an important parameter controlling the concentrations of atmospheric PAHs. Negative values for $m_{3}$ indicate that relatively higher concentrations are observed when the wind is from southerly directions while positive values point northerly directions for high concentrations. The regression parameter related to wind direction $\left(m_{3}\right)$ had positive values and it was statistically significant for the urban site while it was insignificant for the suburban site. The results were consistent with the locations of predominant sources (urban Izmir plume and Aliaga industrial region at north of the suburban and urban sites). It should be noted that the MLR analysis for the urban site is based on a smaller dataset and it may be considered as a limitation on the interpretation of the results from this site.

\subsection{Sources of PAHs}

PAHs are almost entirely anthropogenic in origin and are major byproducts of the incomplete combustion of all types of OM (e.g., gasoline, diesel, and other fuels) [11, 23]. PAH emission sources are primarily categorized as follows: Heavy oil combustion, natural gas combustion, wood and coal combustion, diesel combustion, and vehicles [24].

The winter/summer total PAH (gas + particle) concentration ratios ranged between $1.4(\mathrm{CRB})$ up to $5.9(\mathrm{BaA})$, and $3.1(\mathrm{PHE})$ up to 11.0 (BaP) for suburban and urban sampling sites, respectively. Higher PAH concentrations observed during wintertime could be attributed to the increasing emissions from residential heating $[9,10,15,20$, 25-27]. Different ratios for individual compounds indicated that residential heating emissions have a different profile than summertime emissions (Fig. 2).

The concentration ratios of individual PAHs in ambient samples and source emissions are frequently employed as diagnostic tools to identify their origin in ambient air [28, 29]. Recently, in Northern China emission sources of particle-phase PAHs were identified using a diagnostic plot of FLN/(FLN + PY) versus IcdP/(IcdP + BghiP) [30]. Figure 3 illustrates an example of such diagnostics as a plot of FLN/(FLN + PY) against IcdP/(IcdP + BghiP) for particulate PAHs. Both FLN/(FLN + PY) and IcdP/(IcdP + BghiP) are $>0.5$ in the case of coal/biomass emissions [30]. In Fig. 3, 70\% of the urban samples fall in the left-bottom quadrant, indicating predominant influence of petroleum combustion. Samples appearing in the top-right quadrant, suggest coal/biomass combustion emissions. More than $50 \%$ of the suburban samples also fall in the left-bottom quadrant, indicating significant influence of petroleum combustion (vehicular emissions). However, some of the suburban samples fall in the left-top and right-top quadrants suggesting that coal/biomass combustion is also a major PAH source at this site.

$\mathrm{Li}$ and Kamens [31] observed that the ratio of $\mathrm{BaA} / \mathrm{BaP}$ was 0.5 for gasoline exhaust and 1.0 for both diesel exhaust and wood combustion. In the present study, the $\mathrm{BaA} / \mathrm{BaP}$ ratios were significantly higher for winter (1.05) than summer $(0.70)$ at suburban site. These results indicated that, in addition to traffic emissions, wood and coal combustions are the major PAH sources in winter at the 

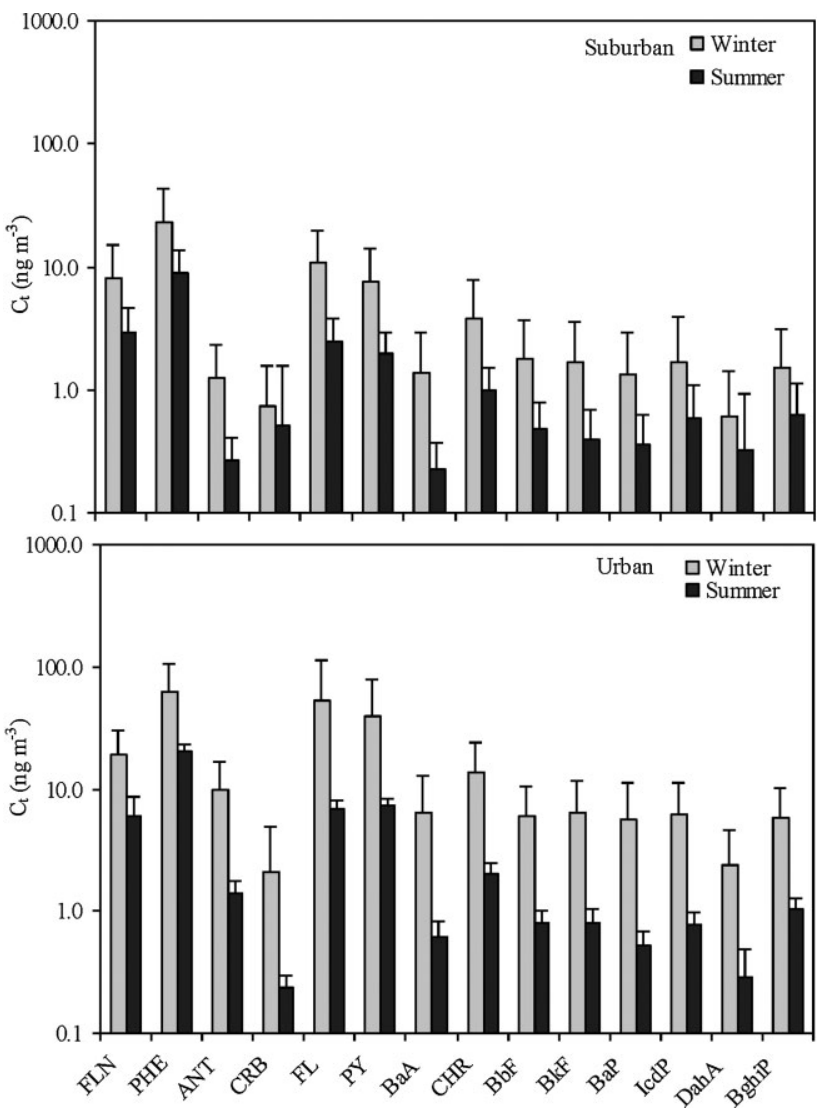

Figure 2. Seasonal variation of individual PAH concentrations in this study. Error bars are $1 \mathrm{SD}$.

suburban site. In summer, traffic emissions dominated at this site. Many other diagnostic ratios for PAHs are used to identify the potential emission sources at different sites. The diagnostic ratios calculated in this study and reported ones by other studies are compared in Tab. 4. In summary, although may be prone to some errors, the diagnostic plot and diagnostic PAH ratios approaches suggested that traffic emissions (petroleum combustion) were the

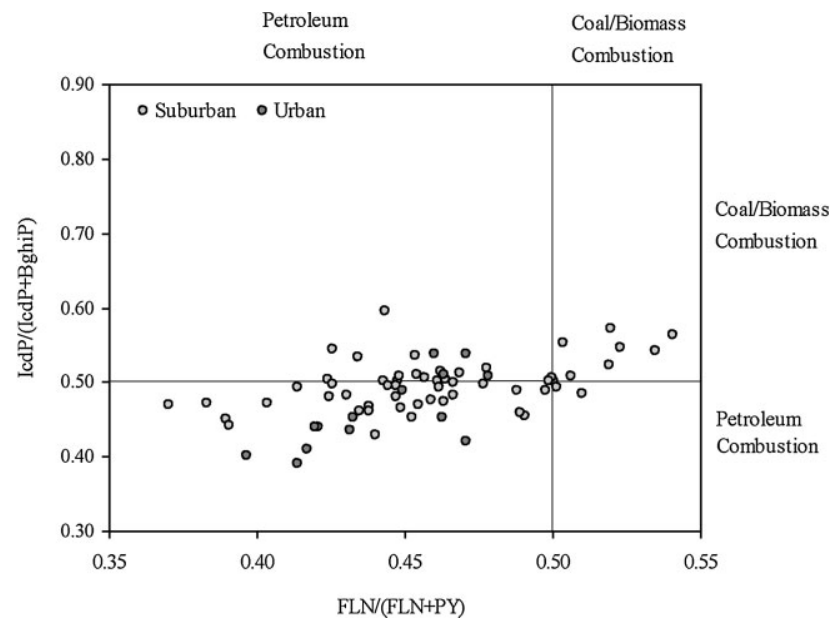

Figure 3. Plot of FLN/(FLN + PYR) against IcdP/(IcdP + BghiP) for PAH source diagnostics. Two dashed lines represent the thresholds for petroleum combustion and coal/biomass burning. dominant PAH sources at all sites for both seasons. During winter, residential heating was also a possible significant PAH source at all sites.

\subsection{Gas-particle partitioning}

Partitioning of atmospheric organic compounds between the gas and particle-phases is parameterized using the gas/particle partition coefficient, $K_{\mathrm{P}}\left(\mathrm{m}^{3} \mu \mathrm{g}^{-1}\right)$ [33]:

$K_{\mathrm{P}}=\frac{C_{\mathrm{p}} / C_{\mathrm{TSP}}}{C_{\mathrm{g}}}$

where $C_{\mathrm{p}}$ and $C_{\mathrm{g}}$ are the organic compound concentrations in the particle and gas-phases, respectively $\left(\mathrm{ng} \mathrm{m}^{-3}\right)$, and $C_{\mathrm{TSP}}$ is the concentration of TSP in the air $\left(\mu \mathrm{g} \mathrm{m}^{-3}\right)$.

The octanol-air partitioning coefficient $\left(K_{\mathrm{OA}}\right)$ can be used to predict $K_{\mathrm{P}}$ with the assumption of predominant distribution process is absorption [33]. The relationship between $K_{\mathrm{P}}$ and $K_{\mathrm{OA}}$ is:

$K_{\mathrm{P}}=\frac{\left(f_{\mathrm{OM}} \mathrm{MW}\right.}{\left.\rho_{\mathrm{OCT}} \zeta_{\mathrm{OCT}}\right) K_{\mathrm{OA}}}$

where $f_{\mathrm{OM}}$ is the fraction of OM phase on TSP, MW the mean molecular weights of octanol and the OM phase $\left(\mathrm{g} \mathrm{mol}^{-1}\right)$, $\rho_{\text {OCT }}$ the density of octanol $\left(0.820 \mathrm{~kg} \mathrm{~L}^{-1}\right), \zeta_{\text {OCT }}$ the activity coefficient of the absorbing compound in octanol, and $\zeta_{\mathrm{OM}}$ is the activity coefficient of the compound in the OM phase. With the assumptions that $\zeta_{\mathrm{OCT}} / \zeta_{\mathrm{OM}}$ and $\mathrm{MW}_{\mathrm{OCT}} / \mathrm{MW}_{\mathrm{OM}}=1$, Eq. (3) can be written as:

$\log K_{\mathrm{P}}=\log K_{\mathrm{OA}}+\log f_{\mathrm{OM}}-11.91$

$K_{\mathrm{OA}}$ values were calculated as a function temperature using:

$\log K_{\mathrm{OA}}=A+\frac{B}{\mathrm{~T}}$

where $A$ is the intercept and $B$ is slope of the temperature regressions given by Odabasi et al. [34] and $\mathrm{T}$ is in $\mathrm{K}$.

The experimental gas-particle partition coefficients $\left(K_{\mathrm{P}}\right)$ for individual PAHs were calculated using Eq. (2). The relationship between $K_{\mathrm{P}}$ and $K_{\mathrm{OA}}$ is expressed using Eq. (4). Plots of $\log K_{\mathrm{P}}$ versus $\log K_{\mathrm{OA}}$ have been used in field and laboratory studies to evaluate the gas-particle partitioning of POPs. A good correlation between $\log K_{\mathrm{P}}$ and $\log K_{\mathrm{OA}}$ and a slope near 1 indicates that octanol is a good surrogate for the partitioning of POPs into aerosol OM [22]. Figure 4 is a plot of $\log K_{\mathrm{P}}$ $\left(\mathrm{m}^{3} \mathrm{ng}^{-1}\right)$ measured at suburban and urban sites versus $\log K_{\mathrm{OA}}$. For the plot containing all data, $K_{\mathrm{P}}$ and $\mathrm{K}_{\mathrm{OA}}$ correlated well $\left(r^{2}=0.80-\right.$ 0.95). The regression parameters, $m$ and $b$ were 0.48 and 6.36 for suburban and 0.89 and 10.7 for urban sites, respectively. For individual samples, $K_{\mathrm{P}}$ and $K_{\mathrm{OA}}$ were also showed a good correlation $\left(r^{2}=0.72-0.97\right.$ and $0.94-0.98$ for suburban and urban sites). The slope values $(m)$ for suburban and urban sites ranged between $0.22-0.74$ and $0.74-1.01$, respectively. The variation of slope values for suburban and urban sites suggests that atmospheric particles for different sites might have different sorbing properties. Good correlation between $\log K_{\mathrm{P}}$ and $\log K_{\mathrm{OA}}$ suggests that $\mathrm{K}_{\mathrm{OA}}$ is a useful predictor for the partitioning of PAHs into aerosol OM. Even though strong correlations were observed between $\log K_{\mathrm{P}}$ and $\log K_{\mathrm{OA}}$, some of the previously reported slopes were significantly different than 1 . As a result of the plots of $\log K_{\mathrm{P}}$ and $\log K_{\mathrm{OA}}$, the slope values of $0.45-0.99$ for OCPs [22], 0.79, 0.99, 0.74, and 0.65 for PAHs, OCPs, PCBs, and PCNs 
Table 4. Diagnostic ratios for ambient air PAHs in this study and previously reported ones for major emission sources

\begin{tabular}{|c|c|c|c|c|c|c|}
\hline \multirow[t]{2}{*}{ Diagnostic ratios (this study) } & \multicolumn{2}{|c|}{ Values (winter/summer) } & \multicolumn{4}{|c|}{ Sources (literature) } \\
\hline & Suburban & Urban & Gasoline & Diesel & Coal & Wood \\
\hline $\mathrm{BaA} / \mathrm{CHR}$ & $0.33 / 0.24$ & $0.43 / 0.30$ & $\begin{array}{c}0.28-1.2^{\mathrm{a})} \\
0.47-0.59^{\mathrm{b})}\end{array}$ & $0.17-0.36^{\mathrm{a})}$ & $\begin{array}{c}1.0-1.2^{\mathrm{a})} \\
1.05-1.17^{\mathrm{b})}\end{array}$ & $0.66-0.92^{\mathrm{b})}$ \\
\hline $\mathrm{BaA} /(\mathrm{BaA}+\mathrm{CHR})$ & $0.24 / 0.19$ & $0.30 / 0.23$ & $0.22-0.55^{\mathrm{c}), \mathrm{d})}$ & $0.38-0.64^{\mathrm{c}), \mathrm{d})}$ & - & $0.43^{\mathrm{d})}$ \\
\hline $\mathrm{BaP} /$ BgiP & $0.84 / 0.61$ & $0.85 / 0.48$ & $0.3-0.4^{\text {a) }}$ & $0.46-0.81^{\text {a) }}$ & $0.9-6.6$ & - \\
\hline IcdP/BghiP & $1.02 / 0.91$ & $0.98 / 0.74$ & $\begin{array}{c}0.27-0.4^{\mathrm{b})} \\
<0.4^{\mathrm{e})}\end{array}$ & $1^{\mathrm{b}), \mathrm{e})}$ & $1.06-1.12^{\mathrm{b})}$ & $0.23-0.33^{\mathrm{b})}$ \\
\hline IcdP/(IcdP + BghiP) & $0.50 / 0.47$ & $0.49 / 0.43$ & $\begin{array}{c}0.21-0.22^{\mathrm{c}), \mathrm{d})} \\
0.18^{\mathrm{b})}\end{array}$ & $0.35-0.70^{\mathrm{c}(\mathrm{)}, \mathrm{b}), \mathrm{d}), \mathrm{e})}$ & $0.56^{\mathrm{e})}$ & $0.62^{\mathrm{d}), \mathrm{e})}$ \\
\hline $\mathrm{BbF} / \mathrm{BkF}$ & $1.08 / 1.37$ & $0.94 / 0.99$ & $1.07-1.45^{\mathrm{b})}$ & $>0.5^{\mathrm{e})}$ & $3.53-3.87^{\mathrm{b})}$ & $0.76-1.08^{\mathrm{b})}$ \\
\hline PHE/ANT & $20.50 / 36.57$ & $7.29 / 15.01$ & $3.4-8^{\mathrm{a})}$ & $7.6-8.8^{\mathrm{a})}$ & $3^{\text {a) }}$ & - \\
\hline FLN/(FLN + PY) & $0.51 / 0.58$ & $0.38 / 0.44$ & $\begin{array}{c}0.40^{\mathrm{b}), \mathrm{d})} \\
<0.5^{\mathrm{e})}\end{array}$ & $\begin{array}{c}0.60-0.70^{\mathrm{b}), \mathrm{d})} \\
>0.5^{\mathrm{e})}\end{array}$ & - & $0.74^{\mathrm{b})}$ \\
\hline $\mathrm{FL} /(\mathrm{FL}+\mathrm{PY})$ & $0.59 / 0.54$ & $0.55 / 0.49$ & $0.40^{\mathrm{c})}$ & $0.60-0.70^{\mathrm{c})}$ & - & - \\
\hline BghiP/BaP & $1.25 / 1.70$ & $1.33 / 2.11$ & $2.5-3.3^{\mathrm{d})}$ & $1.2-2.2^{\mathrm{d})}$ & - & - \\
\hline $\mathrm{BaP} /(\mathrm{BaP}+\mathrm{CHR})$ & $0.24 / 0.25$ & $0.27 / 0.20$ & $0.73^{\mathrm{e})}$ & $0.5^{\mathrm{e})}$ & - & - \\
\hline $\mathrm{PY} / \mathrm{BaP}$ & $8.65 / 6.61$ & $8.26 / 14.74$ & $\sim 1^{\mathrm{e})}$ & $\sim 10^{\mathrm{e})}$ & - & - \\
\hline
\end{tabular}

a) [32].

b) $[21]$.

c) $[29]$.

d) $[28]$.

e) $[23]$.
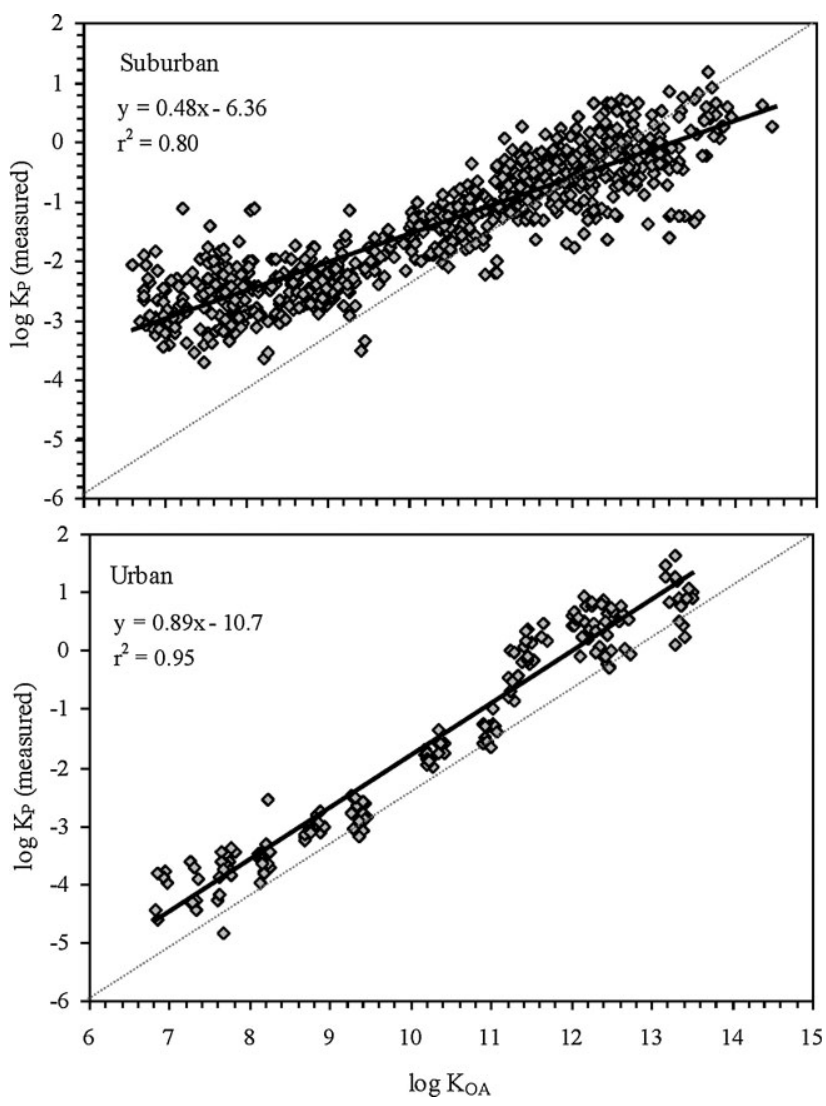

Figure 4. Plots of $\log K_{\mathrm{P}}\left(\mathrm{m}^{3} \mathrm{ng}^{-1}\right)$ measured at suburban and urban sampling sites versus $\log K_{\mathrm{OA}}$. The dashed diagonal line represents a 1:1 relationship (equilibrium).

were reported, respectively [33, 35-37]. Goss and Schwarzenbach [38] have suggested that the slope might deviate from 1 for equilibrium partitioning when $\log K_{\mathrm{P}}$ is plotted versus $\log K_{\mathrm{OA}}$. Deviations from a unity slope may further indicate that atmospheric particles have sorbing properties different from that of octanol.

Strong association of PAHs with soot particles in soot-water systems suggests that besides absorption, adsorption partitioning could also be an important sorption mechanism in the atmosphere. Therefore, the following equation for the overall gas-particle partition coefficient that accounts for both OM absorption and soot carbon adsorption was derived by Dachs and Eisenreich [39]:

$$
\begin{aligned}
K_{\mathrm{P}}= & {\left[\left(f_{\mathrm{OM}} \mathrm{MW}_{\mathrm{OCT}} \zeta_{\mathrm{OCT}}\right) K_{\mathrm{OA}} /\left(\rho_{\mathrm{OCT}} \mathrm{MW}_{\mathrm{OM}} \zeta_{\mathrm{OM}} 10^{12}\right)\right] } \\
& +\left[\left(f_{\mathrm{EC}} a_{\mathrm{EC}}\right) K_{\mathrm{SA}} / a_{\mathrm{AC}} 10^{12}\right]
\end{aligned}
$$

where $f_{\mathrm{EC}}$ is the fraction of elemental carbon in the aerosol, $a_{\mathrm{EC}}$ and $a_{\mathrm{AC}}$ are the specific surface areas of elemental carbon and organic carbon, respectively, and $K_{\mathrm{SA}}$ is the soot-air partition coefficient. Elemental carbon and octanol are the surrogates for the soot carbon in adsorptive partitioning, and $\mathrm{OM}$ in absorptive partitioning, respectively. The $a_{\mathrm{EC}}$ value $\left(62.7 \mathrm{~m}^{2} \mathrm{~g}^{-1}\right)$ was taken from a recent study by Jonker and Koelmans [40]. The average OM contents of PM measured in this study were $53 \pm 20$ and $49 \pm 10 \%$ for suburban and urban sites, respectively. Recently, OM contents were reported to be $53 \%$ [22] and 53.5-62.1\% [41] in the Izmir area. The values measured in the present study were similar to these, however, they were higher than those typically assumed in modeling studies $(10-20 \%)[22,35]$. It was assumed that $a_{\mathrm{EC}} \mid a_{\mathrm{AC}}=1, f_{\mathrm{OM}}=1.6 f_{\mathrm{OC}}$, and $f_{\mathrm{OC}} / f_{\mathrm{EC}}=3$ where $f_{\mathrm{OC}}$ is the fraction of total organic carbon [39, 42].

Dachs et al. [43] have suggested that the thermodynamics-based model recently reported by van Noort [44] can be used to estimate $K_{\mathrm{SA}}$ values for PAHs as a function of supercooled liquid vapor pressure $\left(P_{\mathrm{L}}, \mathrm{Pa}\right)$ and elemental carbon specific surface area $\left(a_{\mathrm{EC}}, \mathrm{m}^{2} \mathrm{~g}^{-1}\right)$ :

$\log K_{\mathrm{SA}}=-0.85 \log P_{\mathrm{L}}+8.94-\log \left(998 / \alpha_{\mathrm{EC}}\right)$

$P_{\mathrm{L}}$ values as a function of temperature can be calculated using:

$\log P_{\mathrm{L}}(\mathrm{Pa})=m_{\mathrm{L}} T^{-1}+b_{\mathrm{L}}$ 

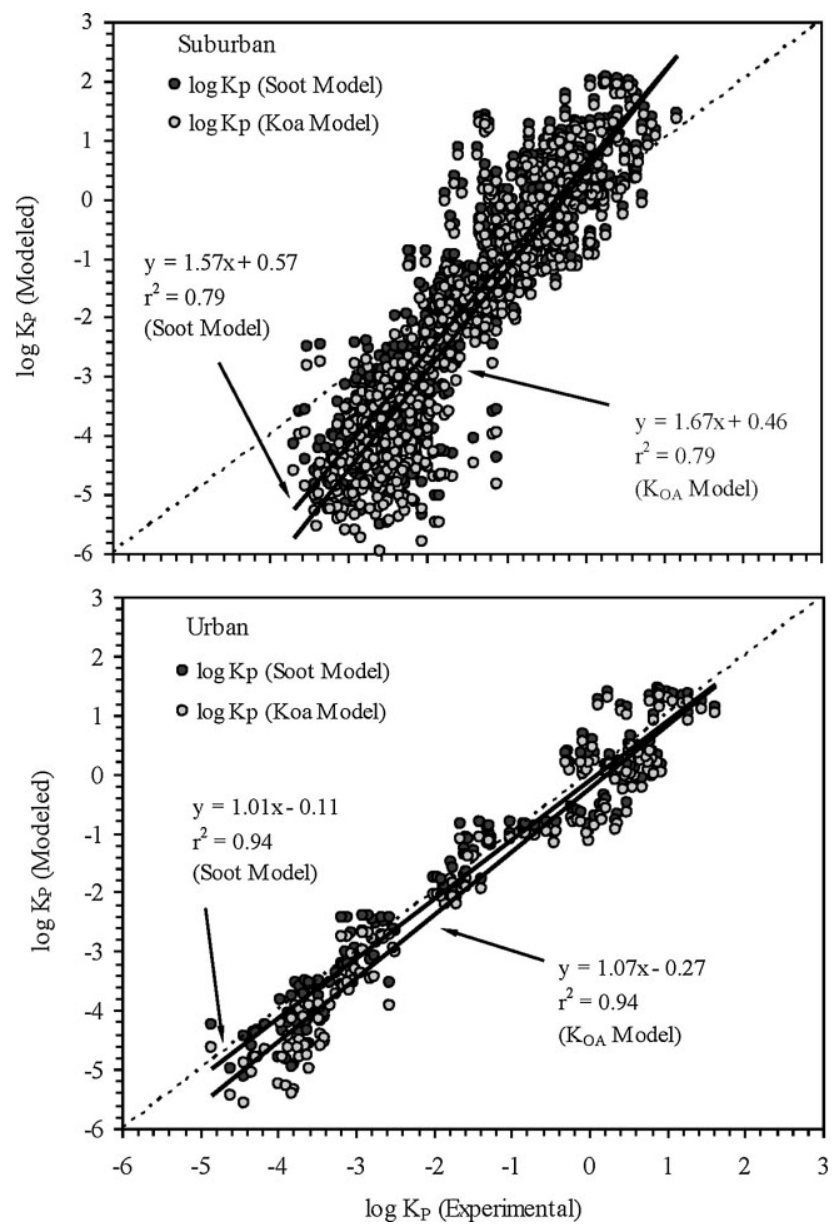

Figure 5. Comparison of the measured and predicted $K_{\mathrm{P}}$ values by two partitioning models. The dashed diagonal line represents a 1:1 relationship.

where $b_{\mathrm{L}}$ is the intercept and $m_{\mathrm{L}}$ is the slope of the temperature regressions [35].

The atmospheric PAH concentrations measured in this study were used to investigate the partitioning of PAHs between particle and gas-phase. Modeled $K_{\mathrm{P}}$ values were calculated using Eq. (4) for absorptive partitioning and Eq. (6) for both absorptive and adsorptive partitioning [34]. The modeled $K_{\mathrm{P}}$ values for absorptive partitioning and for both absorptive and adsorptive partitioning were compared to the measured ones in Fig. 5. The correlations between experimental and modeled $K_{\mathrm{P}}$ values were significant $\left(r^{2}=0.79\right.$ and 0.94 for suburban and urban sites, respectively, $p<0.01$ ). Octanol-based absorptive partitioning model predicted lower partition coefficients especially for relatively volatile PAHs. However, overall there is a relatively good agreement between the measured $K_{\mathrm{P}}$ and soot-based model predictions. Ratios of measured/modeled partition coefficients ranged between 0.15 (BghiP) up to 651 (FLN) $(80 \pm 394$, average $\pm \mathrm{SD}$ ) and 1.2 (CHR) up to 15.5 (FLN) (4.5 \pm 6.0 , average $\pm S D$ ) for the $K_{\mathrm{OA}}$ model in suburban and urban sites, respectively. The soot model predictions were relatively better and measured to modeled ratios ranged between 0.11 (BghiP) up to 232 (FLN) $(30 \pm 141$, average $\pm \mathrm{SD})$ and 0.6 (CHR) up to 5.6 (FLN) $(2.3 \pm 2.7$, average \pm SD) for suburban and urban sites, respectively. Recent studies reported that the soot-based model showed a good predictability at an urban site (Chicago, IL) but underestimated the values at a rural site (Eagle Harbor) by an order of magnitude [45, 46]. It was suggested that characterizing atmospheric soot, determining the temperature dependence of soot-air partitioning, and quantifying the exchangeable fraction of each $\mathrm{PAH}$ on aerosols will help to explain the differences between predicted and observed partition coefficients [46].

It was observed that gas-particle partitioning of PAHs was different for suburban and urban samples. This was evident by the more shallow slopes obtained from the plots of $\log K_{\mathrm{P}}$ versus $\log K_{\mathrm{OA}}$ at the suburban site compared to those for urban sites. Recently, Vardar et al. [45] have reported steeper slopes for lake samples relative to the land samples in Chicago. It was suggested that the observed differences between the lake and land samples may be due to the different properties of particles (i.e., aged particles as a result of longer residence time for lake samples), non-exchangeability and differences in activity coefficients of PAHs. Similarly, in the present study urban samples had steeper slopes than the suburban samples. However, unlike the Chicago samples that had different levels of TSP concentrations (i.e., low for lake and higher for land samples) suburban and urban samples of the present study had similar average TSP concentrations $\left(\sim 70-80 \mu \mathrm{g} \mathrm{m}^{-3}\right.$, respectively). Previous experimental studies have shown that a greater fraction of the higher molecular weight PAHs are associated with fine particles relative to the lower molecular weight compounds [26, 47, 48]. Recent studies indicated that the contribution of wind-entrained soil particles to atmospheric coarse PM is significant at the suburban site $[49,50]$. The contribution of local soil to the coarse PM increases especially the particle-phase concentrations of low molecular weight PAHs. This increase in particle-phase concentration will result in larger $K_{\mathrm{P}}$ values especially for low molecular weight PAHs (Eq. 2) and consequently more shallow slopes for $\log K_{\mathrm{P}}$ versus $\log K_{\mathrm{OA}}$ plots (Fig. 4).

\section{Conclusions}

Ambient air PAH samples were collected at a suburban $(n=63)$ and at an urban site $(n=14)$ in Izmir, Turkey. Higher ambient PAH concentrations were measured in the gas-phase and $\sum_{14} \mathrm{PAH}$ concentrations were dominated by lower molecular weight PAHs. MLR analysis indicated that the meteorological parameters were effective on the measured ambient PAH concentrations. Emission sources of particle-phase PAHs were investigated using diagnostic plots and diagnostic ratios. These approaches have indicated that traffic emissions (petroleum combustion) were the dominant PAH sources at both sites for summer and winter seasons.

Experimental gas-particle partition coefficients $\left(K_{\mathrm{P}}\right)$ were compared to the predictions of octanol-air $\left(K_{\mathrm{OA}}\right)$ and soot-air $\left(K_{\mathrm{SA}}\right)$ partition coefficient models. Octanol-based absorptive partitioning model predicted lower partition coefficients especially for relatively volatile PAHs. However, overall there was a relatively good agreement between the measured $K_{\mathrm{P}}$ and soot-based model predictions.

The authors have declared no conflict of interest.

\section{References}

[1] R. Dabestani, I. N. Ivanov, A Complication of Physical, Spectroscopic and Photophysical Properties of Polycyclic Aromatic Hydrocarbons, Photochem. Photobiol. 1999, 70 (1), 10-34.

[2] M. Odabasi, PhD Thesis, Illinois Institute of Technology, Chicago 1998. 
[3] R. Lohmann, G. Lammel, Adsorptive and Absorptive Contributions to the Gas-Particle Partitioning of Polycyclic Aromatic Hydrocarbons: State of Knowledge and Recommended Parametrization for Modeling, Environ. Sci. Technol. 2004, 38, 37933803.

[4] C. J. Halsall, P. J. Coleman, B. J. Davis, V. Burnett, K. S. Waterhouse, P. Harding-Jones, K. C. Jones, Polycyclic Aromatic Hydrocarbons in U.K Urban Air, Environ. Sci. Technol. 1994, 28, 2380-2386.

[5] M. Odabasi, N. Vardar, A. Sofuoglu, Y. Tasdemir, T. M. Holsen, Polycyclic Aromatic Hydrocarbons (PAHs) in Chicago Air, Sci. Total Environ. 1999, 227, 57-67.

[6] J. Dachs, T. R. Glenn IV, C. L. Gigliotti, P. Brunciak, L. A. Totten, E. D. Nelson, T. P. Franz, S. J. Eisenreich, Processes Driving the Short-Term Variability of Polycyclic Aromatic Hydrocarbons in the Baltimore and Northern Chesapeake Bay Atmosphere, USA, Atmos. Environ. 2002, 36, 2281-2295.

[7] C. L. Gigliotti, P. A. Brunciak, J. Dachs, T. R. Glenn IV, E. D. Nelson, L. A. Totten, S. J. Eisenreich, Air-Water Exchange of Polycyclic Aromatic Hydrocarbons in the New York, New Jersey, USA, Harbor Estuary, Environ. Toxicol. Chem. 2002, 21, 235-244.

[8] M. Mandalakis, M. Tsapakis, A. Tsoga, E. G. Stephanou, Gas-Particle Concentrations and Distribution of Aliphatic Hydrocarbons, PAHs, PCBs and PCDD/Fs in the Atmosphere of Athens (Greece), Atmos. Environ. 2002, 36, 4023-4035.

[9] S. S. Park, Y. J. Kim, C. H. Kang, Atmospheric Polycyclic Aromatic Hydrocarbons in Seoul, Korea, Atmos. Environ. 2002, 36, 2917-2924.

[10] T. Ohura, T. Amagai, M. Fusaya, H. Matsushita, Spatial Distributions and Profiles of Atmospheric Polycyclic Aromatic Hydrocarbons in Two Industrial Cities in Japan, Environ. Sci. Technol. 2004, 38, 49-55.

[11] G. C. Fang, K. F. Chang, C. Lu, H. Bai, Estimation of PAHs Dry Deposition and BaP Toxic Equivalency Factors (TEFs) Study at Urban, Industry Park and Rural Sampling Sites in Central Taiwan, Taichung, Chemosphere 2004, 55, 787-796.

[12] M. Possanzini, V. Di Palo, P. Gigliucci, M. C. T. M. C. Tomasi Sciano, A. Cecinato, Determination of Phase-Distributed PAH in Rome Ambient Air by Denuder/GC-MS Method, Atmos. Environ. 2004, 38, 1727-1734.

[13] M. Tsapakis, E. G. Stephanou, Occurrence of Gaseous and Particulate Polycyclic Aromatic Hydrocarbons in the Urban Atmosphere: Study of Sources and Ambient Temperature Effect on the Gas/Particle Concentration and Distribution, Environ. Pollut. 2005, 133, 147-156.

[14] Y. Tasdemir, F. Esen, Urban Air PAHs: Concentrations, Temporal Changes and Gas/Particle Partitioning at a Traffic Site in Turkey, Atmos. Res. 2007, 84, 1-12.

[15] A. Bozlaker, A. Muezzinoglu, M. Odabasi, Atmospheric Concentrations, Dry Deposition and Air-Soil Exchange of Polycyclic Aromatic Hydrocarbons (PAHs) in an Industrial Region in Turkey, J. Hazard. Mater. 2008, 153, 1093-1102.

[16] M. Akyuz, H. Cabuk, Gas-Particle Partitioning and Seasonal Variation of Polycyclic Aromatic Hydrocarbons in the Atmosphere of Zonguldak, Turkey, Sci. Total Environ. 2010, 408, 5550-5558.

[17] S. Ozcan, M. E. Aydin, Polycyclic Aromatic Hydrocarbons, Polychlorinated Biphenyls and Organochlorine Pesticides in Urban Air of Konya, Turkey, Atmos. Res. 2009, 93, 715-722.

[18] F. Esen, S. S. Cindoruk, Y. Tasdemir, Ambient Concentrations and Gas/Particle Partitioning of Polycyclic Aromatic Hydrocarbons in an Urban Site in Turkey, Environ. Forensics 2006, 7, 303-312.

[19] F. Esen, Y. Tasdemir, N. Vardar, Atmospheric Concentrations of PAHs, Their Possible Sources and Gas-to-Particle Partitioning at a Residential Site of Bursa, Turkey, Atmos. Res. 2008, 88, 243-255.

[20] B. Gevao, J. Hamilton-Taylor, K. C. Jones, Polychlorinated Biphenyl and Polycyclic Aromatic Hydrocarbon Deposition to and Exchange at the Air-Water Interface of Esthwaite Water, a Small Lake in Cumbria, UK, Environ. Pollut. 1998, 102, 63-75.

[21] G. C. Fang, C. N. Chang, Y. S. Wu, P. P. C. Fu, I. L. Yang, M. H. Chen, Characterization, Identification of Ambient Air and Road Dust Polycyclic Aromatic Hydrocarbons in Central Taiwan, Taichung, Sci. Total Environ. 2004, 327, 135-146.
[22] A. Sofuoglu, E. Cetin, S. S. Bozacioglu, G. D. Sener, M. Odabasi, ShortTerm Variation in Ambient Concentrations and Gas/Particle Partitioning of Organochlorine Pesticides in Izmir, Turkey, Atmos. Environ. 2004, 38, 4483-4493.

[23] K. Ravindra, R. Sokhi, R. Van Grieken, Atmospheric Polycyclic Aromatic Hydrocarbons: Source Attribution Emission Factors and Regulation, Atmos. Environ. 2008, 42, 2895-2921.

[24] H. H. Yang, C. M. Chen, Emission Inventory and Sources of Polycyclic Aromatic Hydrocarbons in the Atmosphere at a Suburban Area in Taiwan, Chemosphere 2004, 56, 879-887.

[25] G. Kiss, Z. Varga-Puchony, G. Rohrbacher, J. Hlavay, Distribution of Polycyclic Aromatic Hydrocarbons on Atmospheric Aerosol Particles of Different Sizes, Atmos. Res. 1998, 46, 253-261.

[26] S. Y. Bae, S. M. Yi, Y. P. Kim, Temporal and Spatial Variations of the Particle Size Distribution of PAHs and Their Dry Deposition Fluxes in Korea, Atmos. Environ. 2002, 36, 5491-5500.

[27] J. Schnelle-Kreis, M. Sklorz, A. Peters, J. Cyrys, R. Zimmermann, Analysis of Particle Associated Semi-Volatile Aromatic and Aliphatic Hydrocarbons in Urban Particulate Matter on a Daily Basis, Atmos. Environ. 2005, 39, 7702-7714.

[28] E. Manoli, A. Kouras, C. Samara, Profile Analysis of Ambient and Source Emitted Particle-Bound Polycyclic Aromatic Hydrocarbons from Three Sites in Northern Greece, Chemosphere 2004, 56, 867878.

[29] N. Tang, T. Hattori, R. Taga, K. Igarashi, X. Yang, K. Tamura, H. Kakimoto, et al., Polycyclic Aromatic Hydrocarbons and Nitropolycyclic Aromatic Hydrocarbons in Urban Air Particulates and Their Relationship to Emission Sources in the Pan-Japan Sea Countries, Atmos. Environ. 2005, 39, 5817-5826.

[30] S. Liu, S. Tao, W. Liu, Y. Liu, H. Dou, J. Zhao, L. Wang, et al., Atmospheric Polycyclic Aromatic Hydrocarbons in North China: A Winter-Time Study, Environ. Sci. Technol. 2007, 41, 8256-8261.

[31] C. Li, R. Kamens, The Use of Polycyclic Aromatic Hydrocarbons as Source Signatures in Receptor Modeling, Atmos. Environ. 1993, 27A, 523-532.

[32] M. F. Simcik, S. J. Eisenreich, P. J. Lioy, Source Apportionment and Source/Sink Relationships of PAHs in Coastal Atmosphere of Chicago and Lake Michigan, Atmos. Environ. 1999, 33, 5071-5079.

[33] T. Harner, T. F. Bidleman, Octanol-Air Partition Coefficient for Describing Particle/Gas Partitioning of Aromatic Compounds in Urban Air, Environ. Sci. Technol. 1998, 32, 1494-1502.

[34] M. Odabasi, E. Cetin, A. Sofuoglu, Determination of Octanol-Air Partition Coefficients and Supercooled Liquid Vapor Pressures of PAHs as a Function of Temperature: Application to Gas/Particle Partitioning in an Urban Atmosphere, Atmos. Environ. 2006, 40, 6615-6625.

[35] A. Finizio, D. Mackay, T. F. Bidleman, T. Harner, Octanol-Air Partition Coefficient as a Predictor of Partitioning of Semivolatile Organic Chemicals, Atmos. Environ. 1997, 31, 2289-2296.

[36] R. L. Falconer, T. Harner, Comparison of the Octanol-Air Partition Coefficient and Liquid Phase Vapor Pressure as Descriptors for Particle/Gas Partitioning Using Laboratory and Field Data for PCBs and PCNs, Atmos. Environ. 2000, 34, 4043-4046.

[37] M. Shoeib, T. Harner, Using Measured Ocatanol-Air Partition Coefficients to Explain Environmental Partitioning of Organochlorine Pesticides, Environ. Sci. Technol. 2002, 21, 984-990.

[38] K. Goss, R. P. Schwarzenbach, Gas/Solid and Gas/Liquid Partitioning of Organic Compounds: Critical Evaluation of the Interpretation of Equilibrium Constants, Environ. Sci. Technol. 1998, 32, 2025-2032.

[39] J. Dachs, S. J. Eisenreich, Adsorption onto Aerosol Soot Carbon Dominates Gas-Particle Partitioning of Polycyclic Aromatic Hydrocarbons, Environ. Sci. Technol. 2000, 34, 3690-3697.

[40] M. T. Jonker, A. A. Koelmans, Sorption of Polycyclic Aromatic Hydrocarbons and Polychlorinated Biphenyls to Soot and SootLike Materials in the Aqueous Environment: Mechanistic Considerations, Environ. Sci. Technol. 2002, 36, 3725-3734.

[41] B. Cetin, M. Odabasi, Atmospheric Concentrations and Phase Partitioning of Polybrominated Diphenyl Ethers (PBDEs) in Izmir, Turkey, Chemosphere 2008, 71, 1067-1078. 
[42] S. Ribes, B. Van Drooge, J. Dachs, Ä. Gustafsson, J. O. Grimalt, Influence of Soot Carbon on the Soil-Air Partitioning of Polycyclic Aromatic Hydrocarbons, Environ. Sci. Technol. 2003, 37, 2675-2680.

[43] J. Dachs, S. Ribes, B. V. Drooge, J. Grimalt, Response to the Comment on "Influence of Soot Carbon on the Soil-Air Partitioning of Polycyclic Aromatic Hydrocarbons", Environ. Sci. Technol. 2004, 38, 1624-1625.

[44] P. C. M. van Noort, A Thermodynamics-Based Estimation Model for Adsorption of Organic Compounds by Carbonaceous Materials in Environmental Sorbents, Environ. Toxicol. Chem. 2003, 22, 1179-1188.

[45] N. Vardar, Y. Tasdemir, M. Odabasi, K. E. Noll, Characterization of Atmospheric Concentrations and Partitioning of PAHs in the Chicago Atmosphere, Sci. Total Environ. 2004, 327, 163-174.

[46] E. Galarneau, T. F. Bidleman, P. Blanchard, Seasonality and Interspecies Differences in Particle/Gas Partitioning of PAHs
Observed by the Integrated Atmospheric Deposition Network (IADN), Atmos. Environ. 2006, 40, 182-197.

[47] M. Odabasi, A. Sofuoglu, N. Vardar, Y. Tasdemir, T. M. Holsen, Measurement of Dry Deposition and Air-Water Exchange of Polycyclic Aromatic Hydrocarbons with the Water Surface Sampler, Environ. Sci. Technol. 1999, 33, 426-434.

[48] Y. Tasdemir, F. Esen, Dry Deposition Fluxes and Deposition Velocities of PAHs at an Urban Site in Turkey, Atmos. Environ. 2007, 41, 1288-1301.

[49] S. Yatkin, A. Bayram, Elemental Composition and Sources of Particulate Matter in the Ambient Air of a Metropolitan City, Atmos. Res. 2007, 85, 126-139.

[50] S. Yatkin, A. Bayram, Source Apportionment of PM10 and PM2.5 Using Positive Matrix Factorization and Chemical Mass Balance in Izmir, Turkey, Sci. Total Environ. 2008, 390, 109-123. 